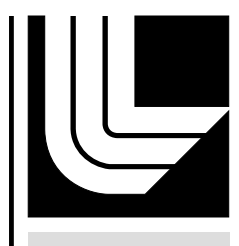

LAWRENCE LIVERMORE N A TIO NAL LABORATORY

Report on coating from Teer

J.N. Florando

November 9, 2006 
This document was prepared as an account of work sponsored by an agency of the United States Government. Neither the United States Government nor the University of California nor any of their employees, makes any warranty, express or implied, or assumes any legal liability or responsibility for the accuracy, completeness, or usefulness of any information, apparatus, product, or process disclosed, or represents that its use would not infringe privately owned rights. Reference herein to any specific commercial product, process, or service by trade name, trademark, manufacturer, or otherwise, does not necessarily constitute or imply its endorsement, recommendation, or favoring by the United States Government or the University of California. The views and opinions of authors expressed herein do not necessarily state or reflect those of the United States Government or the University of California, and shall not be used for advertising or product endorsement purposes.

This work was performed under the auspices of the U.S. Department of Energy by University of California, Lawrence Livermore National Laboratory under Contract W-7405-Eng-48. 
Author: Jeff Florando 8/2006

\section{Re: Report on coating from Teer}

\section{Coating Parameters}

A trial coating run has been performed at Teer Coating LTD to assess the use of a barrel coating system as a viable option to coat multilayer spheres. Hollow glass spheres (3M $\mathrm{K} 15)$ ranging in diameter from $70-120$ microns were cleaned in a process using a $0.1 \mathrm{M}$ $\mathrm{HCl}$ solution. Comparative photos before and after the cleaning process are shown in figure 1 .

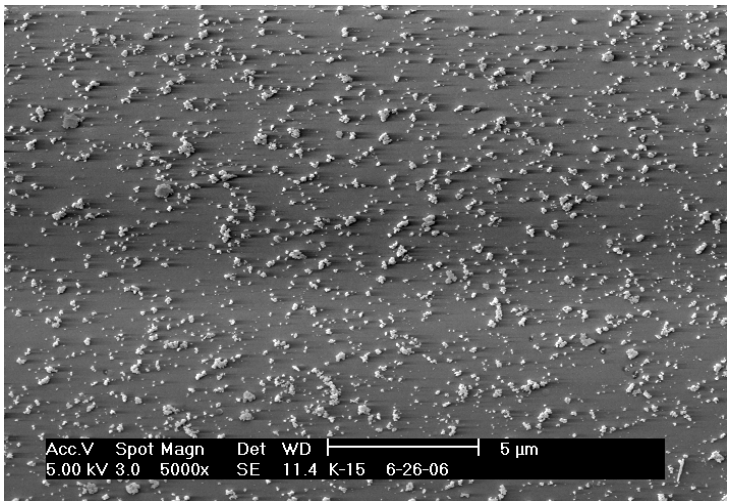

a)

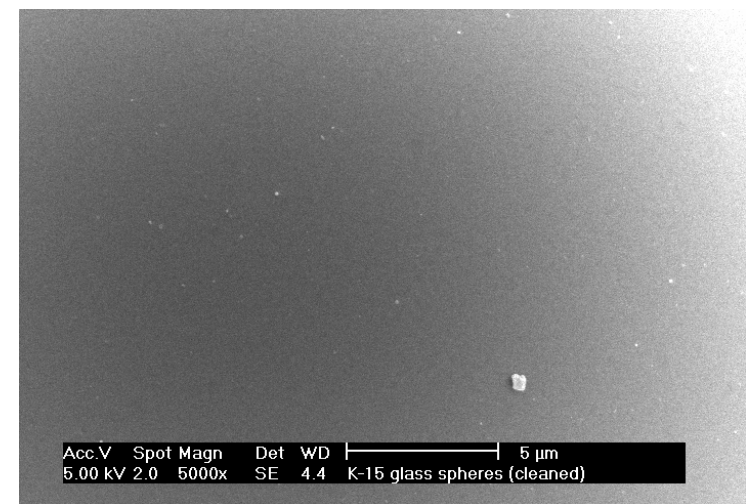

b)

Figure 1- a) surface of glass microsphere before cleaning b) surface of glass microsphere after cleaning

Approximately, 2 liters of cleaned spheres were sent to Teer for the trial coating in their barrel coater. A picture of barrel coating system is shown in figure 2 . The coating process was one layer of titanium followed by one layer of aluminum. The target thickness for each layer is $500 \mathrm{~nm}$, however, no rate runs were performed to calibrate the parameters. Each layer was sputtered for 10 hours, for a total of 20 hours.

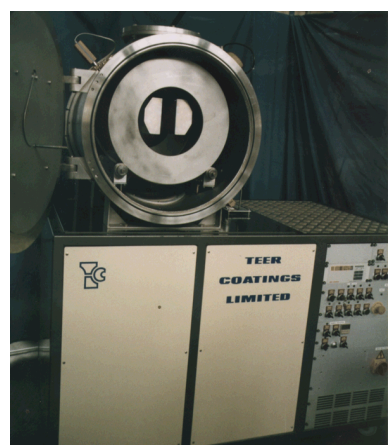

a)

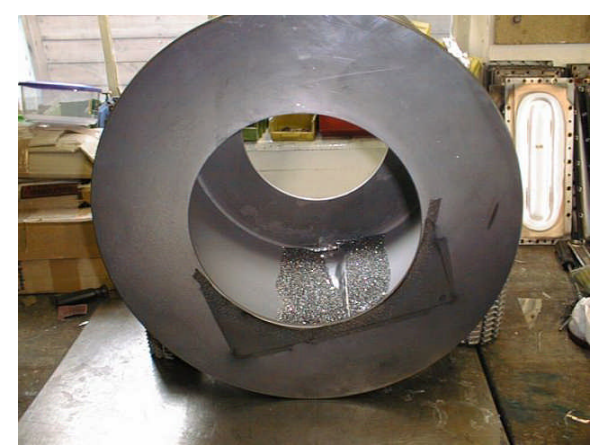

b)

Figure 2- a) Picture of the barrel coating system b) Close-up picture of the barrel with some material inside (not our microspheres) 


\section{SEM Analysis}

After the coating process, the coated spheres were sent back to LLNL for SEM analysis. In order to quickly examine the coating in cross-section, the spheres were broken with a spatula. Photos of the broken spheres are shown in Fig 3. One sphere was chosen to look at the uniformity around the sphere.

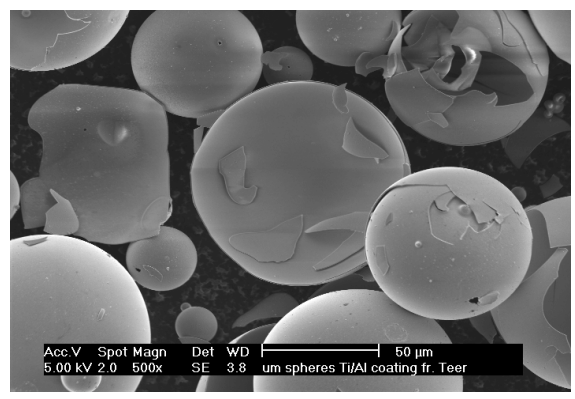

Figure 3- Overview of coated microspheres, some were broken to look at cross-section

As can be seen in Figure 4, there is fairly good uniformity around the sphere. You can also distinguish between the Ti (lighter) and Al layers, however it appears the Al is quite a bit thicker. This result is not too surprising because in general $\mathrm{Al}$ deposits faster than $\mathrm{Ti}$. Figure 4 also shows the surface morphology of the top Al layer. Although it is still quite rough, it appears to be smoother than the Teer coating with just Al on glass.
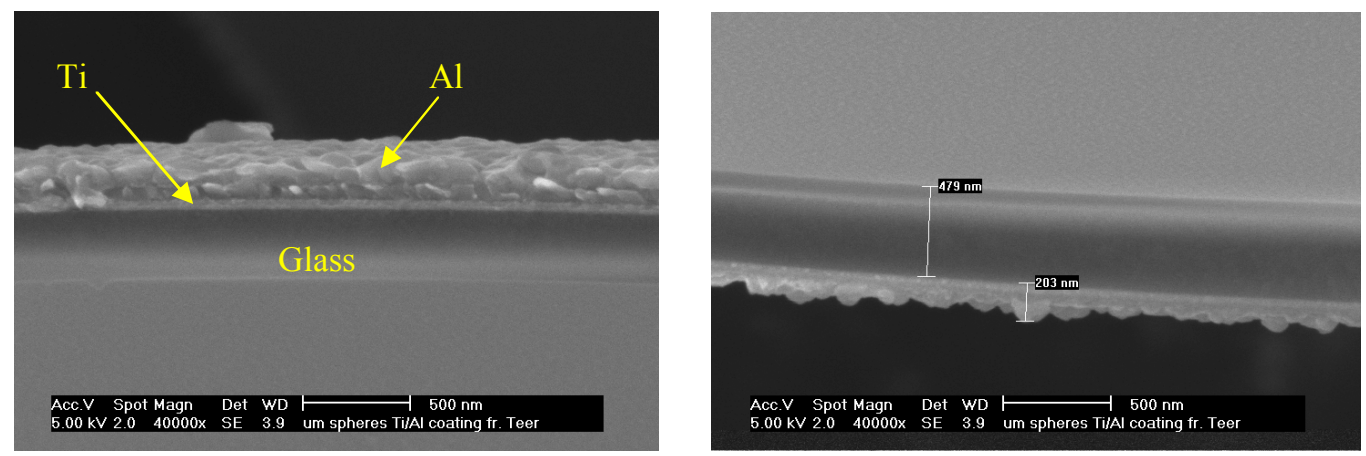

a)

b)

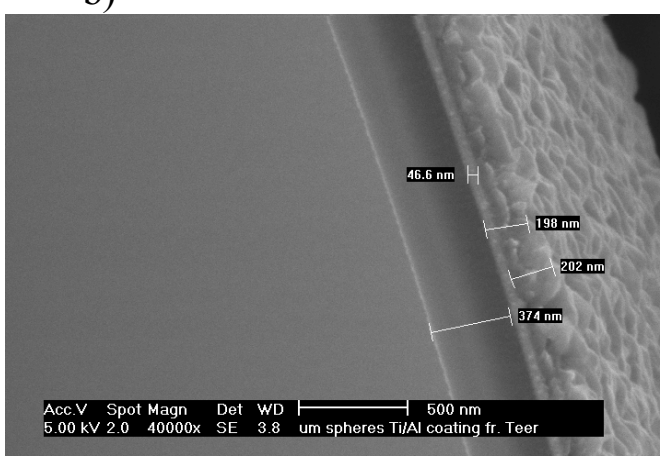

c)

Figure 4- Cross-section views showing the $\mathrm{Ti}$ and $\mathrm{Al}$ layer thicknesses at different points along the perimeter of the coated sphere a) 12 o'clock b) 6 o'clock c) 3 o'clock. The thickness appears to be fairly uniform around sphere, indicating that the balls were rolling well during the deposition process. 


\section{Recommendation}

Based on this analysis, we believe that the barrel coating system can produce uniform coatings and is the correct deposition configuration to coat large quantities of microspheres. However, given the variation in thickness and surface roughness of the current coatings, the process needs further development in order to produce the high quality multilayers required. Other variables including optimum material combinations, layer pair thickness, optimum surface preparation, cleaning, and coating parameters need to be optimized to fully asses this technology. 